\title{
Laparoscopic Live Donor Nephrectomy in Patients Surgically Treated For Morbid Obesity
}

\author{
Anibal W. Branco, Alcides J. Branco Filho, William Kondo
}

Section of Urology and General Surgery, Cruz Vermelha Hospital, Curitiba, Parana, Brazil

\begin{abstract}
In the past, morbid obesity was considered a relative contraindication to renal donation; however, more recent publications have shown that laparoscopic renal surgery is safe and effective for obese donor nephrectomy. We report the performance of a bariatric surgery before the kidney donation in 2 patients in order to improve their medical condition and to reduce their surgical risk to the transplantation procedure. After bariatric surgery, both donors lost more than $30 \%$ of their initial corporal weight and their donation procedure was successfully performed, with uneventful postoperative courses.
\end{abstract}

Key words: laparoscopy; nephrectomy; living donors; morbid obesity; bariatric surgery

Int Braz J Urol. 2007; 33: 377-9

\section{INTRODUCTION}

Patients who are morbid obese are much more likely to have health problems than persons who maintain a healthy weight. Consequently, these individuals need medical treatment, and bariatric surgery is currently the only effective therapy for this disease. In the past, morbid obesity was considered a relative contraindication to renal donation (1); however, more recent publications have shown that laparoscopic renal surgery is safe and effective for obese donor nephrectomy $(1,2)$. We report on 2 patients in whom we preferred to perform the Roux-en-Y gastric bypass before the laparoscopic kidney donation in order to treat their medical condition, reducing their surgical risk to the live donor nephrectomy procedure.

\section{CASE REPORT}

Case 1 - A 23-year-old male donor with body mass index (BMI) $40.9 \mathrm{~kg} / \mathrm{m}^{2}$ (weight $=121 \mathrm{~kg}$; height
$=1.72 \mathrm{~m}$ ) and no co-morbidities underwent a laparoscopic Roux-en-Y gastric bypass losing $38 \mathrm{~kg}$, 4 months after the bariatric surgery. Then, he was scheduled for the left hand-assisted laparoscopic live donor nephrectomy, which was uneventful, with an operative time (OT) of 75 minutes, a warm ischemia time (WIT) of 1.8 minutes, and an estimated blood loss (EBL) of $100 \mathrm{cc}$. He was discharged in the first postoperative day (Figure-1). The serum creatinine of the recipient 5 months after the procedure was 1.1 $\mathrm{mg} / \mathrm{dl}$ and the donor was weighting $76 \mathrm{~kg}$ (BMI 25.7 $\mathrm{kg} / \mathrm{m}^{2}$ ).

Case 2 - A 54-year-old female donor with BMI $48.7 \mathrm{~kg} / \mathrm{m}^{2}$ (weight $=120 \mathrm{~kg}$; height $\left.=1.57 \mathrm{~m}\right)$ and mild hypertension had undergone a laparoscopic bariatric surgery in another institution, losing only 20 $\mathrm{kg}$ in 4 months. She came to our service and was submitted to a laparoscopic revisional bariatric surgery, reducing the size of the gastric pouch and increasing the length of the Roux limb. Three months after surgery her BMI was $32.4 \mathrm{~kg} / \mathrm{m}^{2}$ (Weight $=80$ $\mathrm{kg}$ ) and she underwent a pure left laparoscopic donor 
nephrectomy (Figure-2) with an OT of 90 minutes, a WIT of 2.2 minutes, and an EBL of $80 \mathrm{cc}$. She was discharged in the postoperative day 1 . Two months after the kidney donation, the serum creatinine of the recipient was $1.1 \mathrm{mg} / \mathrm{dL}$ and the BMI of donor was $32 \mathrm{~kg} / \mathrm{m}^{2}$, with no need for antihypertensive medication.

\section{COMMENTS}

Morbid obesity is an important public health problem. It is associated with serious co-morbidities (hypertension, diabetes, peripheral resistance to insulin, dyslipidemia, etc.), it shows a high prevalence globally, and it is associated with a high mortality rate (3). Moreover, when morbid obese patients need any surgical procedure, they present a significant challenge for the laparoscopic surgeon. In addition to the technical challenges of positioning and instrumentation, these patients are reported to have a propensity for postoperative and anesthetic complications (2).

Population studies have shown that obesity is associated with increased risk for proteinuria, and the development of proteinuria signals a marked increased risk to develop renal failure. Acceptance of obese individuals as living kidney donors is controversial related to possible increased risk for surgical complications and concern that obesity may contribute to longterm renal disease (4).

Chow et al. (1) analyzed non-obese (BMI < $30)$ and morbidly obese patients (BMI $\geq 30)$ referred for hand-assisted donor nephrectomy finding similar shortened hospital stays and surgical times for both groups. They concluded hand-assisted donor nephrectomy is safe and effective, not increasing morbidity in morbid obese donors.

Jacobs et al. (2) compared markedly obese $(\mathrm{BMI}>35)$ and ideal-size control (BMI < 30) donors scheduled for laparoscopic nephrectomy and they observed the donor operations in the markedly obese were significantly longer by an average of $40 \mathrm{~min}$ utes, obese donors were more likely to require conversion to open nephrectomy than ideal-size donors ( $7.3 \%$ vs. $0 \%$ ) and postoperative complications were equal in the two groups, although the obese donors'

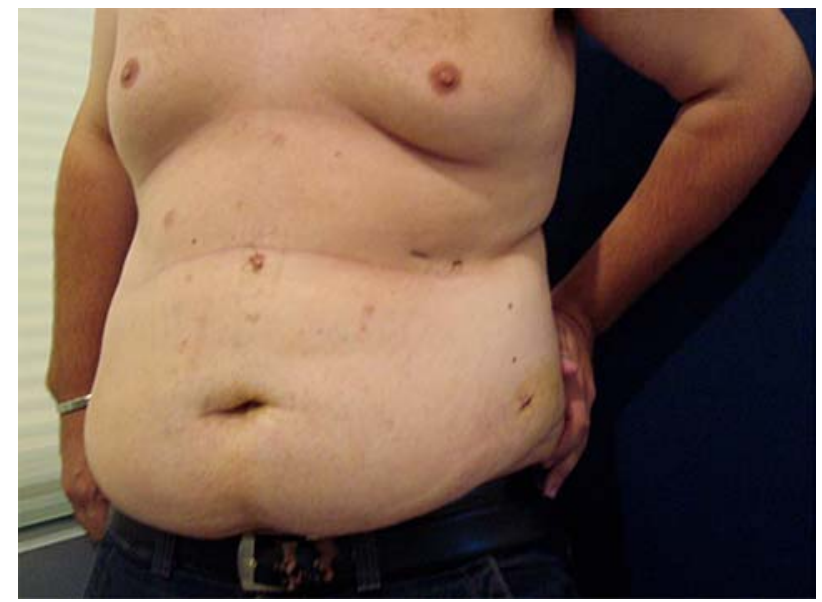

Figure 1-Patient on the day of discharge.

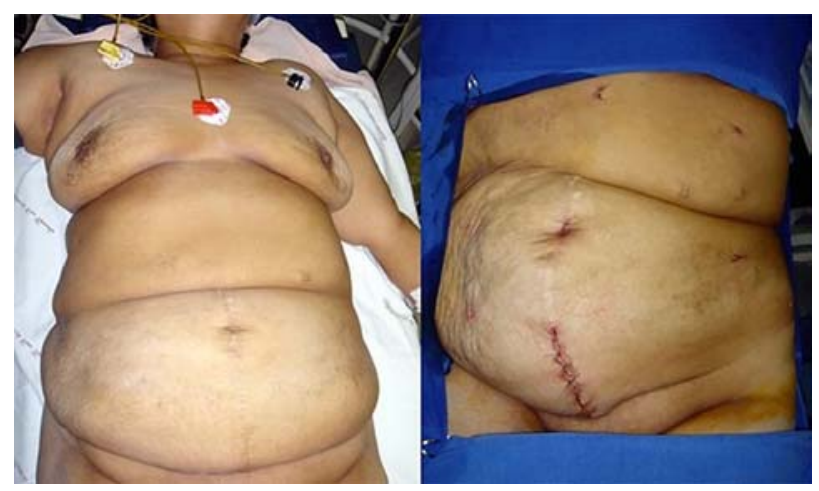

Figure 2 - Patient on the surgical table and final aspect of the surgery. The infra-umbilical incision was used to remove the kidney because she already had this surgical scar due to a previous hysterectomy.

complications tended to be cardiopulmonary problems. They concluded that despite the longer operative time, the increased port size requirement and the higher conversion rate in the markedly obese group, these differences are fairly small, and the procedure of laparoscopic donor nephrectomy itself appears appropriate to consider for the markedly obese renal donor.

\section{CONFLICT OF INTEREST}

None declared. 


\section{REFERENCES}

1. Chow GK, Prieto M, Bohorquez HE, Stegall MD: Handassisted laparoscopic donor nephrectomy for morbidly obese patients. Transplant Proc. 2002; 34: 728.

2. Jacobs SC, Cho E, Dunkin BJ, Bartlett ST, Flowers JL, Jarrell B, et al.: Laparoscopic nephrectomy in the markedly obese living renal donor. Urology. 2000; 56: 926-9.
3. Silvestre V, Ruano M, Dominguez Y, Castro R, GarciaLescun MC, Rodriguez A, et al.: Morbid obesity and gastric bypass surgery: biochemical profile. Obes Surg. 2004; 14: 1227-32.

4. Heimbach JK, Taler SJ, Prieto M, Cosio FG, Textor SC, Kudva YC, et al.: Obesity in living kidney donors: clinical characteristics and outcomes in the era of laparoscopic donor nephrectomy. Am J Transplant. 2005; 5: 1057-64.

Accepted after revision: December 15, 2006

\section{Correspondence address:}

Dr. Anibal Wood Branco

Rua das Palmeiras, 170 Apto. 201

Curitiba, PR, 80620-210, Brazil

Telephone +55 $41242-6543$

E-mail:anibal@awbranco.com.br

\section{EDITORIAL COMMENT}

Long term follow-up of renal obese donors is limited, as obesity has been considered relative exclusion criteria until recently. While obese donors showed a trend to higher mean arterial pressure and a higher glomerular filtration rate, there were no significant differences from normal donors (1). Another aspect is the possibility that they may be at greater risk for developing type II diabetes mellitus later in life and the unknown impact of nephrectomy on the obese patients who subsequently develops diabetes or hypertension (2).

The idea of performing a bariatric surgery in such group of donors may be very helpful for not only reducing the morbidity of the donation itself but also offering some effective therapy for morbid obesity.

This special group of donors should be submitted to a very strict selection criterion and who are highly motivated to donate could be accepted. The selected criteria should be based upon blood pressure, family history of diabetes and cardiovascular disease and reinforcing the importance of a careful and long term follow-up.

\section{REFERENCES}

1. Gracida C, Espinoza R, Cedillo U, Cancino J: Kidney transplantation with living donors: nine years of follow-up of 628 living donors. Transplant Proc. 2003; 35: 946-7.

2. Heimbach JK, Taler SJ, Prieto M, Cosio FG, Textor SC, Kudva YC, et al.: Obesity in living kidney donors: clinical characteristics and outcomes in the era of laparoscopic donor nephrectomy. Am J Transplant. 2005; 5: 1057-64.

Dr. William Nahas

Division of Urology

University of Sao Paulo Medical School

Sao Paulo, SP, Brazil

wnahas@uol.com.br 